\title{
Design of a versatile diagnostic test bench of an electric vehicle's powertrain for educational purpose using a Model- based system engineering
}

\author{
Hicham El hadraoui ${ }^{1, *}$, Ahmed Chebak $^{1}$, and Mourad Zegrari ${ }^{1,2}$ \\ ${ }^{1}$ Green Tech Institute, Mohammed VI Polytechnic University, Benguerir, Morocco \\ ${ }^{2}$ Hassan II University of Casablanca, Morocco
}

\begin{abstract}
With the rapid development of the sustained economy, the sales of electric vehicles are increasingly pressing, and today the maintenance has severely impeded the marketing and usage of electric vehicles. The maintenance procedure for electric vehicles is considered a critical process, tell its affect the security and availability directly with the passengers. many of research efforts are still devoted to develop and innovate on electric traction systems diagnostic and prognostic. Furthermore, in high-quality education, especially engineering education, topics concerning the vital and actual concerns should comprise more than theoretical knowledge, in purpose to close the relationship between the present technology and the student's environment and provides hands-on engineering experience and training of general engineering skills, in order to avoid non-standard, unskilled maintenance work. The paper presents a first step towards designing a test bench of a fully electric vehicle's Powertrain used for research and educational purposes using modelbased systems engineering (MBSE) and systems modelling language (SysML) thorough the CESAM architecting and modelling framework. As the first step of the system's design, an operational perspective layout of the diagnostic and prognostic's test bench is built and presented using this technique.
\end{abstract}

\section{Introduction}

Energy deficiency and degradation of ecosystems have emerged as two of the most pressing global concerns in latest years, forasmuch, the transportation sector is among the top contributors in the greenhouse gases (GHG) emission. In fact, conventional vehicles are driven by an internal combustion engine (ICE) using fossil fuels; they emit carbon monoxide, nitrogen oxides, hydrocarbons and carbon dioxide, causing a greenhouse effect on the climate and a toxic effect on human health [1,2]. According to statistical data, an increase of two-thirds of oil consumption comes from transport industries [3], which is highly unfavourable to the sustainable development of human society [4,5]. In a comparison of sources of $\mathrm{CO} 2$ emissions in $\%$ in the United States-2019, Fig. 1 shows that transportation accounts for over a quarter of total $\mathrm{CO} 2$ emissions [6]. Driven by the global emission reduction targets of the Paris Climate Agreement, to address these rising issues, the development of electric vehicles (EVs) seems to be a more futuristic and sustainable solution and has already attracted many automobile manufacturers and several countries have committed massive talents and material resources in this sector [7,8]. European Union countries and their automobile manufacturers have scheduled to limit sales of the fuel vehicle; the Chinese government has promulgated the EV industry development plan (2021-2035), in which the goals are set for the next 15 years. China's EVs production and sales were 1.366 and 1.367 million units respectively in 2020, according to the China Association of Automobile Manufacturers (CAAM) $[9,10]$. It begins with the Hybrid Electric Vehicles (HEVs) as an advantageous alternative of the Conventional ICE vehicles' since they are less polluting, these vehicles are considered as a transition phase to the fully electric vehicles (EVs). However, EVs are still less technologically mature than the ICE vehicle, and many researches must be devoted to this field. Compared to conventional vehicles, EVs are more expensive, and have a lower range rating, longer charging time, and lower power density. Furthermore, as EVs become an unavoidable trend, more issues with the electrical grid are emerging, such as degraded power quality and the need to upgrade existing power systems as a result of charging EVs on a large scale by connecting them to the grid, which is an issue that necessitates a consistent work in the future [11]. Training a new generation of engineers in this sector is critical as expenditures in transportation electrification projects increase. However, the professionals in this field must be knowledgeable with a wide range of disciplines, including vehicle dynamics, electric machines, power electronics, energy storage systems, automotive engineering, software packages, new intelligent control techniques, diagnostic and prognostic engineering. Furthermore, accurate vehicle tests and hardware in the loop (HIL) simulations for electric vehicles facilitate a hands-on, intuitive, and interactive experience. In fact, the electric vehicle drive

\footnotetext{
*Corresponding author: hicham.elhadraoui@um6p.ma
} 
is often regarded as a complicated system, as it is an innovative high-tech revolutionary product [8], where the necessity to use modern design methods for such a system, such as System engineering (SE). Systems engineering is a multidisciplinary and composite method to ensure that designed systems are implemented, used, and retired effectively [12], and it is referenced by ISO 12588, EIA-632, and IEEE 1220 [13]. Fig. 2 demonstrates the ranges of these standards which categorize processes regardless of the application domain of system engineering.

This work is a first step toward the objective of a global project to develop and build a versatile test bench of an electric car's powertrain for educational aim. Our system of interest (SOI) is considered as a subsystem in the EV complex system which interact with others subsystems of the EV. This paper presents an operational analysis of our system, following a MBSE grid and CESAM as a primary framework and SysML as modelling language. In the first section, we present the aim of our study, and a second section explains the SE, MBSE approach and the architectural design framework used in this work. Section 3 presents the operational analysis of the studied system using the upmentioned MBSE framework and SysML modelling language.

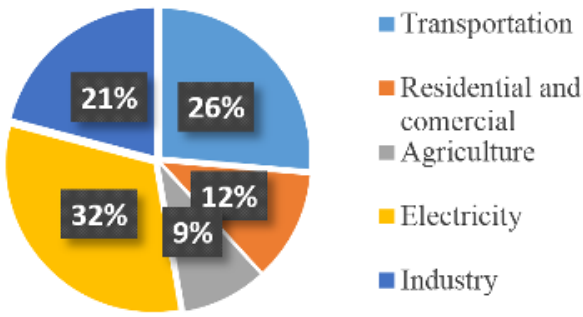

Fig. 1. Total U.S GHG emissions by sector in 2019 [5].

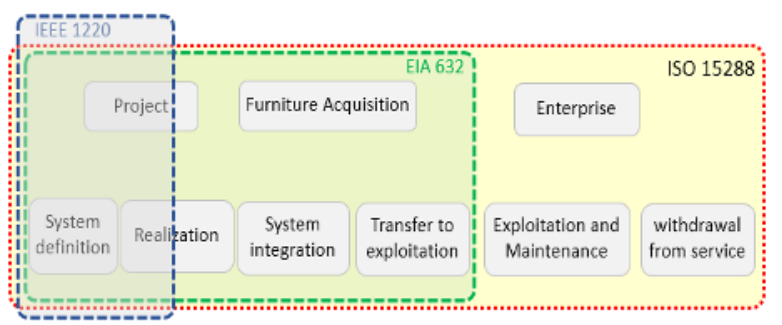

Fig. 2. The three system engineering standards and their ranges.

\section{Motivation, objectives and general approach}

The proposed educational test bench's specific goal is to enhance the appeal and the creative approaches for the automotive technical education in addition to supplement theoretical teachings, expose and stimulate students', developers and researchers interest on the process of designing diagnostic and prognostic systems for electric cars. Among the consequence of the project is to provide new instructional materials with improved quality focusing on the latest breakthroughs in automobile technology. In terms of technology, the project exposes engineering students to components currently used in EVs, such as super capacities, batteries, power converters, sensors, traction machines [14]. Besides, the project covers also design tools for new control strategies. The test bench project targets are Master's degree students in mechanical, electrical or electronic engineering, PhD students, and researchers. A proposed teaching methodology comprises three different learning levels:

Basic level: This level contains a digital simulation of the physical system including the whole components of the powertrain, from the energy storage system to the electrical motors, including the different electronic drives and the vehicle dynamics.

The aim of this learning phase is to present the state of art and latest technology for diagnosing the electric vehicle's powertrain, contemporary education components will be added and should assist to eliminating obstacles, provide innovative activities and facilitate comprehension of such a complicated procedures existing in present vehicles, through a series of exercises and manipulations of the simulated system.

Advanced level: consisting of manipulating a physical laboratory workbench of the electric Powertrain of an electric vehicle. It includes an energy storage system, two principals power electronics inverters, and two different electric motors, one for emulating the inertia and motion resistances of the vehicle and the other as the traction machine, thorough a switching part. The idea for adding the switching part is to have such two in one electric traction Powertrain, by the mean of switching the role of each motor to have two configurations to be tested. Using this pre-installed and equipment and assisted by a supervisor, the students can test the control strategies developed and simulated in a previous stage.

Experts level: the traction system could be reconfigured, and novel developed control strategies could be simulated, tested and integrated into interior stages. This level is allowed for $\mathrm{PhD}$ students and researchers to develop novel solutions. in this level, the user must have already explored the latest artificial intelligence learning algorithm, combined with the characteristics in the process of electric vehicle operating.

\section{Definitions, State of art and discussion}

A system may be described as combination of distinct objects interacting and connected parts, according to a set of rules. At the same time, the entire group is also engaging with its external environment in order to produce a cohesive whole [12].

A complex system is system whom behaviour is intrinsically difficult to model due to the dependencies, competitions, relationships, or other types of interactions between their parts or between a given system and its environment. Complex systems contain various characteristics that result out of such linkages, such as highly nonlinear, development, random organization, adaptability, and interaction mechanisms. Throughout many situations, it is advantageous to show 
a rather system as a network where the nodes represent the components and connections to their interactions.

Model-based systems engineering (MBSE) is a structured technique for supporting the creation of complex systems' requirements, design, analysis, verification, and affirmation. MBSE places models first at core of system design, as opposed to documentcentric engineering [13].

In a digital-modeling context, MBSE offers benefits that document-based systems engineering does not. MBSE in a digital-modeling environment provides advantages that document-based systems engineering cannot provide. Many papers are produced by various writers in a document-based method to record the system's design through diverse stakeholder perspectives, such as system behaviour, software, hardware, safety, security, or other disciplines. A single source of truth for the system is produced using a digitalmodeling method, with discipline-specific views of the system are developed using the same components.

A digital-modeling environment also establishes an uniform standards-based method to documenting the system, which can be programmatically verified to eliminate discrepancies in the models and ensure that all stakeholders follow the same set of rules. This shared modeling framework enhances system analysis and decreases the amount of flaws introduced in a typical D method. The ability to analyze digitalized system data across disciplines ensures that adjustments and new information and design decisions are consistently communicated to all stakeholders. When MBSE is correctly implemented, development risks are reduced overall [15].

In general, MBSE is joined with several concepts: model, systems thinking, systems engineering, process, tool and framework: A model is a simplified depiction of something, such as a mathematical, graphical or physical representation which abstracts reality to remove some of its complexities, a system must be modelled with less detail so that its structure and behavior can be seen and its complexity can be managed. To put it another way, models must adequately reflect the system, and the system must validate the models.

Systems thinking is a technique of viewing at a system as part of a bigger system rather than as a selfcontained unit. It is not the same as a systematic adherence to excellent planning, gathering statistics, or being methodical[16].

The systems engineering is an interdisciplinary field of engineering and engineering management that focuses on how to design, integrate, and manage complex systems over their life cycles, system thinking is used at the heart of SE organize this corpus of knowledge, and enable the items to operate with each other in a synergistic manner to perform a meaningful function, when it comes to dealing with large or complicated projects, issues such as requirement analysis, stability, logistics, organization of interprofessional workforce, verification and validation, supportability, and several other disciplines are far more hard to address.
In these kind of tasks, system engineering handles on work processes, optimisation methodologies, and risk management tools to straddles the border between technical and human-centered disciplines.

A process is a logical series of actions carried out to attain a certain goal. A process's structure allows for many layers of aggregation to satisfy various decisionmaking requirements. A procedure specifies "WHAT" should be done rather than "HOW" each job should be completed [13].

Process tasks are carried out utilizing methods at all levels. Every method is also a process in and of itself, with a set of tasks to be completed for that approach. In other words, at one level of abstraction, the "HOW" becomes the "WHAT" at a lower degree of abstraction.

A tool is an item when used in conjunction with a certain approach, can improve the task's efficiency, in condition to be used correctly and by someone with the necessary skills and training. The goal of a tool should be to make the "HOWs" easier to achieve. It improves the "WHAT" and "HOW" in a larger meaning. Computer- or software-based are the most common tools that adopted to assist systems engineering [17].

The usage of a framework is required to apply the MBSE method. A framework is a reference and a guideline for organizing all of the components of a system's design from several perspectives.

In this paper, we discuss the MBSE grid framework [15], and CESAM Systems Architecting methodology [16-18]. It is a CESAMESTM architectural and modeling framework that meets with INCOSE standards. It is an architecture and modeling framework developed by CESAMESTM, which complies with INCOSE standards[19]. The overall system's architecture can be defined using the following elements [20]:

\section{- A three architectural visions}

Fig. 3 offers an overview of the processes in our study's investigation and modelling. The system perimeter identification and operational perspective are the first two phases in the SOI, which are proceeded by a requirements analysis and a final needs analysis. The SOI's Measures of Effectiveness are determined throughout this process. To be able to use the SysML modeling language, we employ these three major viewpoints in our research, but we enhance them based on behavioral perspectives.

- A hierarchical organization

The goal of this illustration is to show how the amount of elements and details increase while viewers progress from one perspective to another. Beginning with "Why?" and proceeding into "What?" as well as "How?" the order whereby the research questions are posed is crucial. When it comes to practice, it's essential to differentiate "by order" from "successively" in order to prevent conflicting logic.

- A global architecture matrix

The global architecture of the model can take the form of a matrix widely recognized as the CESAM system architectural matrices, which contains all of the previously explained architectural features, it protects the model's performance by establishing a clear association of the various representations. In addition, 
the MBSE grid framework overlook the depth and intricacy of the model, as well as the ambiguity of the linkages between levels of reasoning.

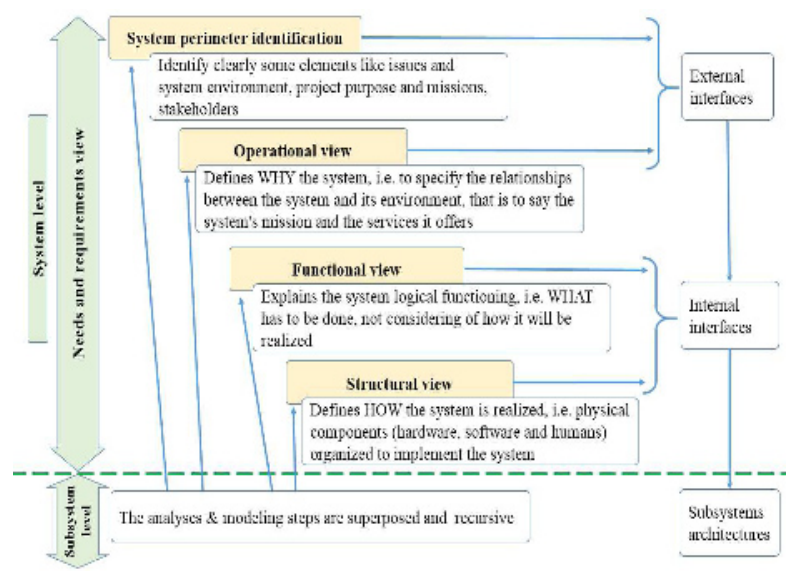

Fig. 3. Analysis and modeling process adapted from [21].

\section{Design of the proposed system}

This research uses an MBSE grid and a CESAM method to illustrate the idea and problem of an electric vehicle's powertrain test bench of diagnostic and prognostic for educational purpose. The research project model was built using the CAMEO tool and is based on SysML. The first and most important phase in the system development process is understanding the demands of the stakeholders and establishing the system perimeter [22]. This work's goal is to get to the end of this phase. It entails gathering the necessary data to ensure that the SOI's objectives are met. This step's key phases may be summed as follows:

- Identifying the expectations of the stakeholders,

- Creating the PFMSO diagram,

- Determining the SOI's interfaces with the different outside stakeholders,

- Defining operational use scenarios.

\subsection{Establish a list of stakeholders demands}

Individuals and entities engaged are likely to offer an originator of needs. Table 1 categorizes the various stakeholders and their demands into operational, functional, performance, and constraint categories. Fig. 4 depicts the primary needs diagram, which depicts the stakeholders' overall expectations from the SOI.

It should be noted that this word is the continuation and extension of the control test bench in [23], with was analyzed and designed using the same approach, on that way, ranging from the stakeholder's needs and the requirements diagram to the whole lifecycle are having either characteristics in common or in extension.

\subsection{PMFSO Diagram of the SOI}

The PFMSO diagram of the examined system is shown in Fig. 5. We specify a block to depict the system, and requirements to clarify the mission and the purpose; the system and the mission are connected by a bond of satisfaction, rather, the mission and the purpose are connected by a link of derivation or association.
An association with stereotypes such as "missions is made to clarify. The mission can be fine-tuned if required by setting requirements to describe sub missions, assigning them an identity, and associating them with a stereotype to explain.

Table 1. Stakeholders' needs classification.

\begin{tabular}{|c|c|c|c|}
\hline $\begin{array}{l}\text { Need } \\
\text { ID }\end{array}$ & Need Description & Category & \begin{tabular}{|c|}
$\begin{array}{c}\text { Stakeho- } \\
\text { lder }\end{array}$ \\
\end{tabular} \\
\hline N1 & $\begin{array}{l}\text { Simulating the functions } \\
\text { of the electric drivetrain }\end{array}$ & Operational & $\begin{array}{l}\text { End user, } \\
\text { designer }\end{array}$ \\
\hline $\mathbf{N 2}$ & $\begin{array}{c}\text { Replicating and } \\
\text { validating the functions } \\
\text { of an electric powertrain }\end{array}$ & Operational & $\begin{array}{l}\text { End user, } \\
\text { designer }\end{array}$ \\
\hline N3 & $\begin{array}{l}\text { Collection of the data and } \\
\text { archiving it in a data-base }\end{array}$ & Operational & End user \\
\hline N4 & $\begin{array}{l}\text { Displaying of the } \\
\text { parameters of the SOI }\end{array}$ & Functional & End user \\
\hline N5 & $\begin{array}{l}\text { Enabling remote access } \\
\text { to the system }\end{array}$ & Operational & $\begin{array}{l}\text { End user, } \\
\text { designer }\end{array}$ \\
\hline N6 & $\begin{array}{l}\text { Maintaining many } \\
\text { aspects of the SOI, such } \\
\text { as power, performance, } \\
\text { and diagnostic reliability }\end{array}$ & $\begin{array}{l}\text { Functional, } \\
\text { Performance }\end{array}$ & End user \\
\hline N7 & $\begin{array}{l}\text { Testing and evaluating } \\
\text { various diagnostic } \\
\text { algorithms for different } \\
\text { portions of the SOI }\end{array}$ & Functional & End user \\
\hline N8 & $\begin{array}{c}\text { Studying different } \\
\text { diagnostic algorithms for } \\
\text { the whole components of } \\
\text { the SOI }\end{array}$ & Functional & End user \\
\hline N9 & $\begin{array}{l}\text { enabling energy recovery } \\
\text { when braking/slowdown }\end{array}$ & Functional & End user \\
\hline N10 & $\begin{array}{l}\text { Supplying the power } \\
\text { transfer from the traction } \\
\text { motor to the ESS }\end{array}$ & Performance & End user \\
\hline N11 & $\begin{array}{l}\text { Enabling maximal energy } \\
\text { transmission from the } \\
\text { ESS to the actuators }\end{array}$ & Performance & $\begin{array}{l}\text { End user, } \\
\text { designer }\end{array}$ \\
\hline $\mathbf{N 1 2}$ & $\begin{array}{l}\text { Testing and validating of } \\
\text { new smart technology to } \\
\text { improve the SOI lifecycle }\end{array}$ & Functional & End user \\
\hline $\mathbf{N 1 3}$ & Having a modular design & Constraint & End user \\
\hline N14 & $\begin{array}{l}\text { Having an optimal } \\
\text { dimensions }\end{array}$ & Constraint & End user \\
\hline N15 & $\begin{array}{c}\text { Having a diversity in the } \\
\text { ESS }\end{array}$ & Constraint & End user \\
\hline N16 & $\begin{array}{c}\text { Respecting the } \\
\text { environmental standards }\end{array}$ & Constraint & \begin{tabular}{|c|} 
Standards \\
entities
\end{tabular} \\
\hline N17 & $\begin{array}{c}\text { Respecting safety } \\
\text { standards } \\
\end{array}$ & Constraint & \begin{tabular}{|c|} 
Standards \\
entities
\end{tabular} \\
\hline
\end{tabular}

Table 2. Stackholder's participation in the lifecycle phases.

\begin{tabular}{|c|c|c|c|c|c|}
\hline $\begin{array}{c}\text { Lifecycle/St- } \\
\text { ackholders }\end{array}$ & Design & $\begin{array}{c}\text { Insta- } \\
\text { llation }\end{array}$ & $\begin{array}{c}\text { Exploi- } \\
\text { tation }\end{array}$ & $\begin{array}{c}\text { Main- } \\
\text { tenance }\end{array}$ & $\begin{array}{c}\text { With- } \\
\text { drawal }\end{array}$ \\
\hline Designer & $\checkmark$ & $\checkmark$ & & $\checkmark$ & $\checkmark$ \\
\hline End user & & & $\checkmark$ & & \\
\hline Standards & $\checkmark$ & $\checkmark$ & $\checkmark$ & $\checkmark$ & $\checkmark$ \\
\hline $\begin{array}{c}\text { Maintenance } \\
\text { team }\end{array}$ & & $\checkmark$ & & $\checkmark$ & \\
\hline
\end{tabular}




\subsection{Defining operational use case}

The operational use cases illustrate the operations that the system should provide to each one of its consumers. This step might appear self-evident, but it assists in defining stakeholders' intentions and, as a consequence, describes demands both more precisely and clearly. Fig. 6 give an illustration of the operating stage use case., The SOI must provide the three major stated support service, to the end users which are:

- Dynamic Simulation of the electric vehicles' powertrain,

- Testing the diagnostic strategies and the predictive algorithms for prognostic on the electric vehicles' powertrain,

- Testing for validation of the new developed control strategies on the different parts of the electric vehicles' powertrain.

\subsection{Powertrain Life cycle, boundaries and external participants}

One of the major goals of this project is to define the SOI's whole lifespan and then display its immediate surroundings and bounds. Table 2 illustrates the phases of the system's lifecycle, as well as the responsibilities and ramifications of each stakeholder, while Fig. 7 depicts the lifecycle of the powertrain test bench.

The whole system's architecture is shown in Fig. 8, with the various modules ranging from the energy storage system to the electric traction motor and emulated load. As aforementioned, a switching part is added in the purpose to have such two in one electric traction powertrain, by switching the role of two different types of motors to have two configurations to be tested.

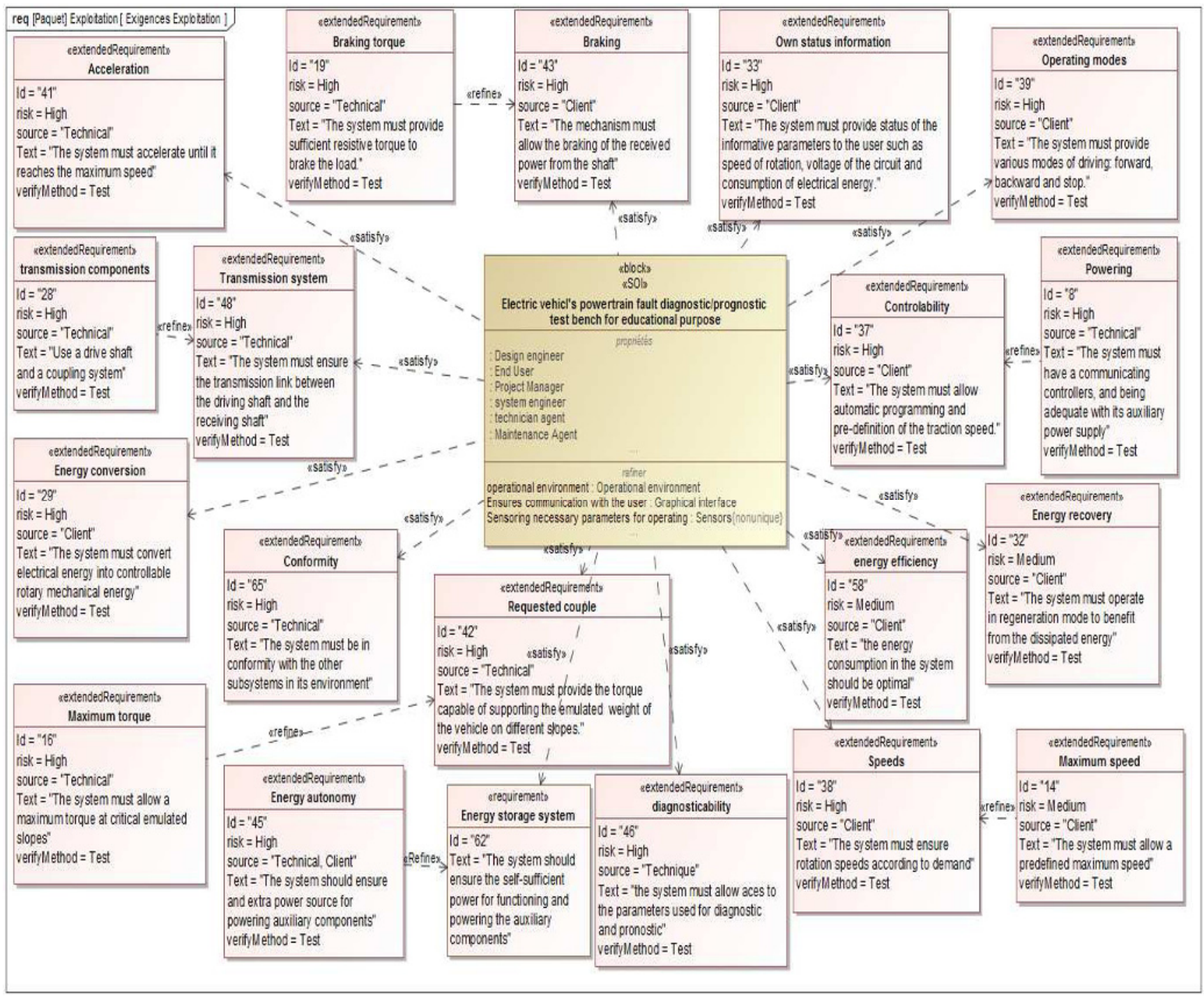

Fig. 4. Requirements diagram of the SOI. 


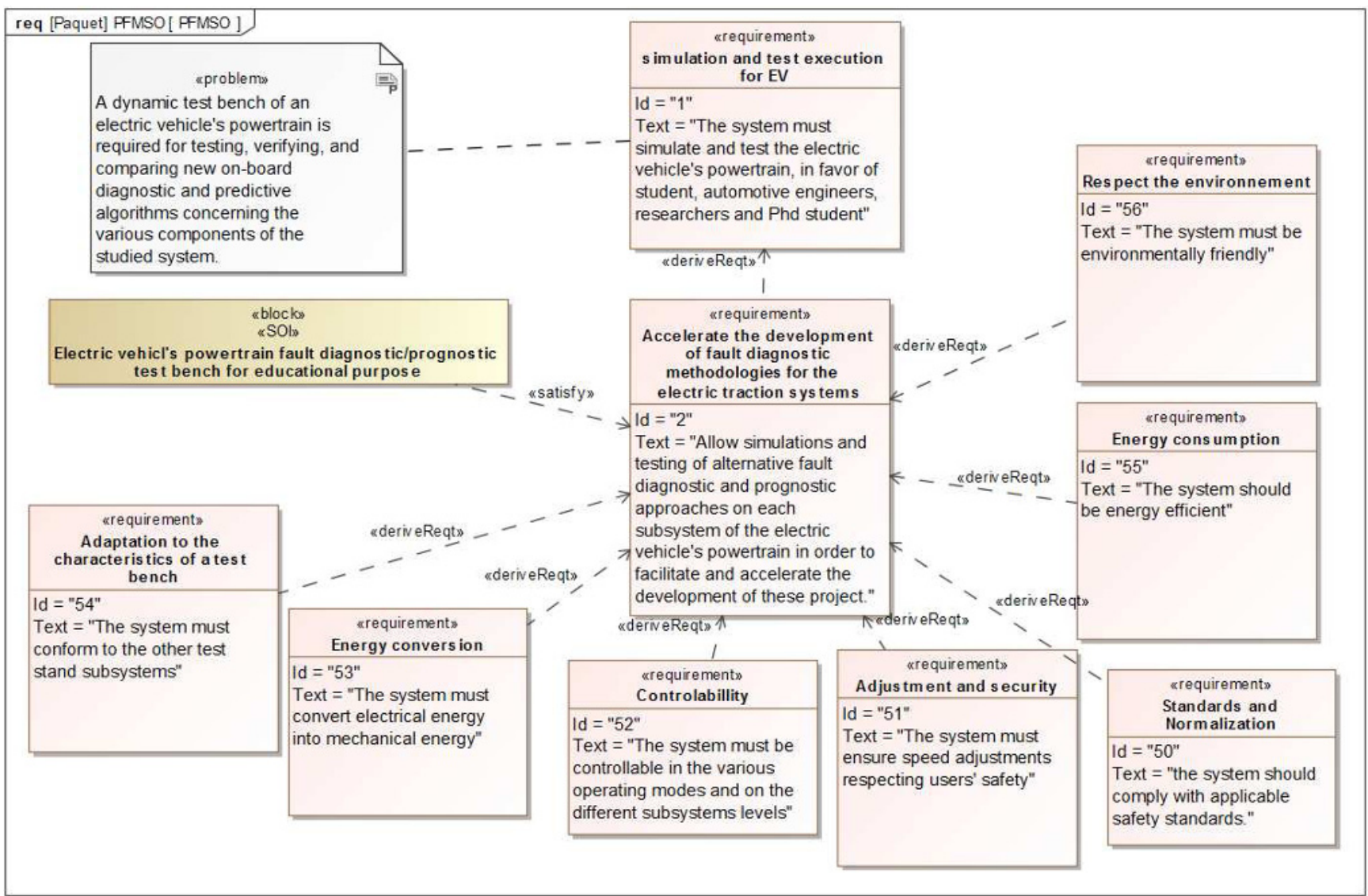

Fig. 5. PMFSO diagram of the designed SOI.

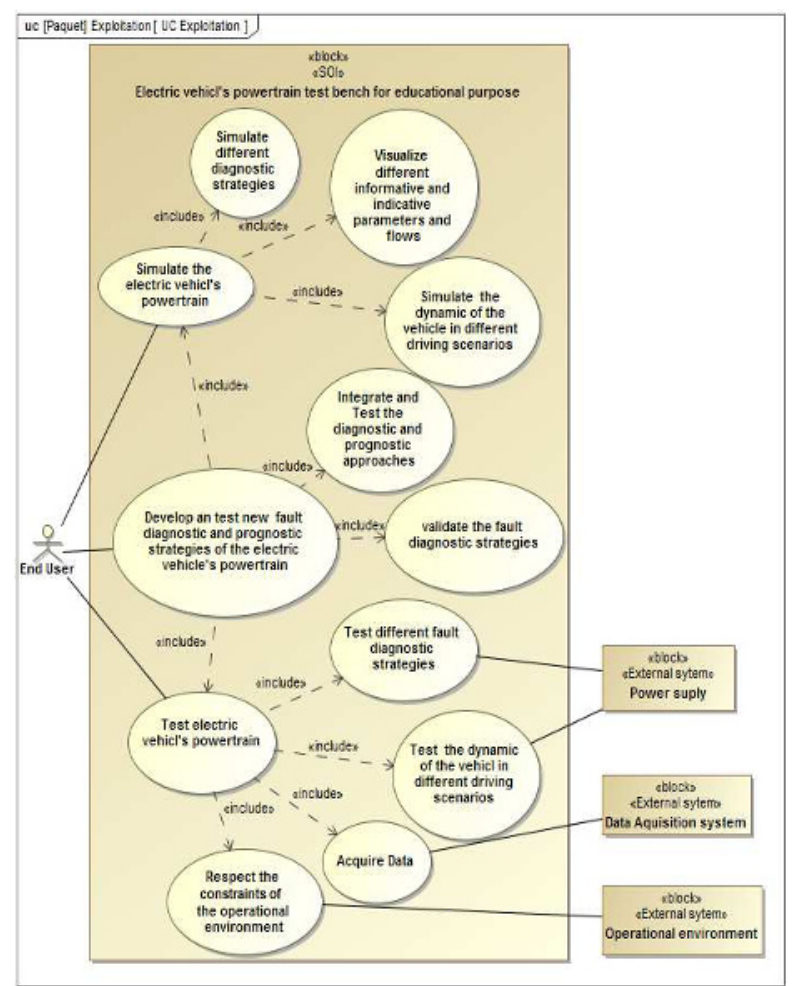

Fig. 6. Use case diagram of the SOI.

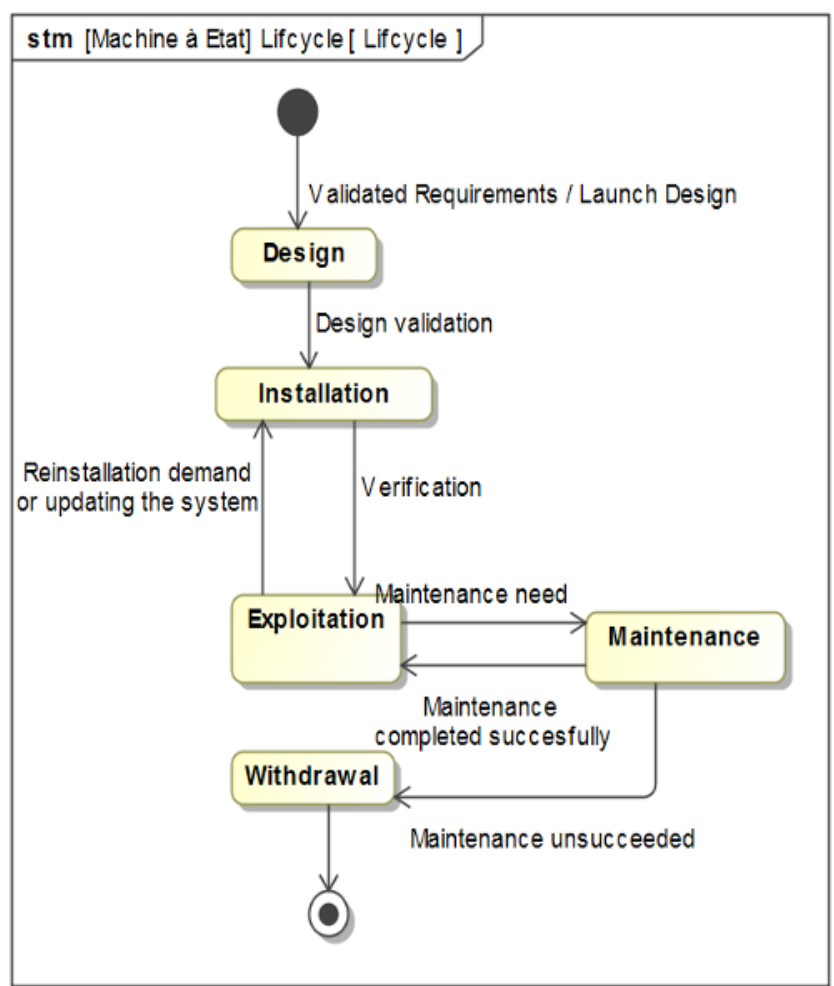

Fig. 7. Lifecycle diagram of the SO 


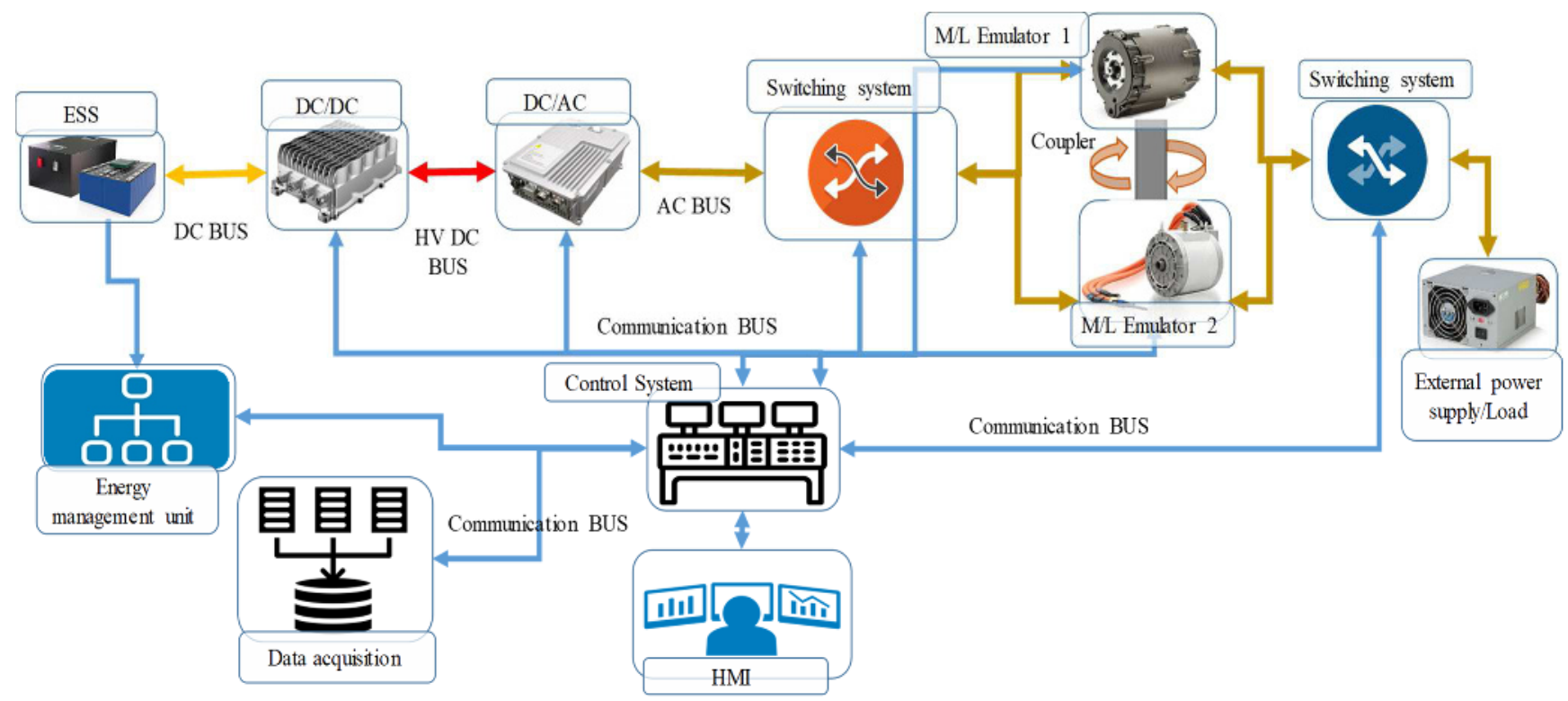

Fig. 8. Bloc diagram definition of the proposed system adapted from [23].

\section{Conclusion}

This paper presents the first step in introducing the design of an electric traction system's fault diagnostic and prognostic test bench for educational purposes. The deliverable achieved is indeed the development of an electric traction system's test bench using a model-based system, when building such a complicated system, many factors and variables must be addressed and handled. As a result, the use of the SE and MBSE approaches appears to be critical for ensuring optimization and adaptability across the whole process, particularly in research projects and development efforts. As previously stated, in order to assure the entire design and execution of the traction system, technical investigations on further pillars that correlate towards each functional and constructional vision must be conducted in future works. Our short-term goal is to expand the suggested system's investigations using the aforementioned MBSE frameworks to provide a functional analysis. Our longterm future work is to extend the project to construct a wireless remote monitoring system, and on this basis, we develop a remote problem diagnostic function, based on the real demands of the system as well as build a virtual reality environment and expand the project to some of the other electric vehicle subsystems.

\section{References}

1. Z. Li, A. Khajepour, J. Song, Energy, 182 (2019).

2. Y. Zou, S. Wei, F. Sun, X. Hu, Y. Shiao, Energy (Oxford), 100, pp. 25-39, 2016.

3. V. Krithika and C. Subramani, International Journal of Energy Research, 42, 5, 1789-1812, (2018).

4. J. Du et al., Energy, 176, pp. 309-319, (2019).

5. X. Sun, Z. Li, X. Wang, C. Li, Energies, 13, (2020).

6. O. US EPA, Sources of GHG Emissions, (2015).

7. R. R. Kumar, K. Alok, Journal of Cleaner Production, 253, p. 119911, (2020.
8. B. Reuter, D. Gleyzes, M. Lienkamp, SAE Technical Paper, (2014).

9. W. Cai, X. Wu, M. Zhou, Y. Wang, Automotive Innovation 4, no.1, pp. 3-22. (2021).

10. Z. Hao, Z. Li, H. Ni, S. Lv, X. Wang, Y. Zhu, IOP Conf. Ser: Earth Environ. Sci., 791, (2021).

11. M. R. Khalid, M. S. Alam, A. Sarwar, M. S. Jamil Asghar, eTransportation, 1, (2019).

12. A. Doufene, A. Dauron, H. G. C. G, D. Krob, INCOSE International Symposium, 24, (2014).

13. D. Krob, CESAM: CESAMES Systems Architecting Method A Pocket Guide, (2017).

14. S. Friedenthal, A. Moore, R. Steiner, A Practical Guide to SysML: the systems modeling language, (2014).

15. D. Mazeika, A. Morkevicius, A. Aleksandraviciene, System of Systems Engineering Conference (SoSE), pp. 1-6, (2016).

16. R. Cloutier, B. Sauser, M. Bone, A. Taylor, IEEE Transactions on Systems, Man, and Cybernetics: Systems, 45, pp. 662-674, (2015).

17. J. A. Estefan, "Survey of Model-Based Systems Engineering Methodologies.", INCOSE, 2008.

18. B. P, Douglass, Agile Systems Engineering. Morgan Kaufmann, 1st Edition, Sep. 2015.

19. J.D. Piques, Embedded Real Time Software and Systems (ERTS), p. 17, 2014.

20. N. Guennouni, N. Machkour, and A. Chebak,17th International Conference on Electrical Machines, Drives and Power Systems, (2021).

21. A. Doufene, H. G. Chalé-Góngora, D. Krob, Complex Systems Design \& Management, Berlin, Heidelberg, pp. 105-123, (2013).

22. A. Poullikkas, Renewable and Sustainable Energy Reviews, 41, pp. 1277-1287, 2015.

23. H. El hadraoui, A. Chebak, and M. Zegrari, Global Power, Energy and Communication (GPECOM), pp. 233-239, (2021). 